\title{
School environment factors were associated with BMI among adolescents in Xi'an City, China
}

Ming $\mathrm{Li}^{1,2^{*}}$, Michael J Dibley ${ }^{3}$ and Hong Yan ${ }^{2}$

\begin{abstract}
Background: School environment influences students' behaviours. The purpose of this research was to identify school environment factors associated with BMI.

Methods: A cross-sectional study was conducted among 1792 school-aged adolescents from 30 schools in six districts in Xi'an City in 2004. Height and weight were taken from students by trained field staff. School environment characteristics such as physical factors (school facilities, school shops and fast food outlets in school area), school curricula and policies were collected from school doctors using school environment questionnaire. School environment factors were identified in linear mixed effect models with BMI as outcome and adjusted for socio-demographic factors.

Results: After adjusted for socio-demographic factors, BMI was associated with the availability of soft drinks at school shops, the availability and the number of western food outlet in the school vicinity. School curricula such as sports-meeting and health education session were also associated with BMI.

Conclusions: Urgent actions are needed to address the obesogenic elements of school environments. Community and school policy makers should make efforts for students to avoid exposure to fast food outlet in school area and soft drinks at school shops, and to improve school curricula to promote healthy behaviours.
\end{abstract}

\section{Background}

Overweight and obesity among adolescents in China, especially in urban populations, has become a public health priority [1]. A survey in Xi'an City, a major urban area in northwest China with a population of 7 million, has revealed that $16 \%$ of the adolescents aged 11-17 were either overweight or obese based on the cutoffs of International Obesity Task Force (IOTF) [2].

Overweight and obesity are the result of positive energy balance. Although individual behavioural factors such as low levels of physical activity and/or dietary behaviours are thought to contribute to the epidemic of obesity, broader understanding of environmental factors has been extended. The Analysis Grid for Environments Linked to Obesity dissects the environment into micro or macro, in which the former includes factors related to school, workplaces, homes and neighbourhoods [3]. Davidson and Birth put forward a conceptual framework that suggests children's behaviour is embedded in the

\footnotetext{
* Correspondence: ming.li@unisa.edu.au

'Division of Health Sciences, University of South Australia, Australia

Full list of author information is available at the end of the article
}

wide environment at community, school, and family levels [4]. Schools exert a great influence on children's behaviour since students spend most of their waking time during a day at schools (typically 8-12 hours per day). School time is the key developmental period in which children adopt health behaviours as lifetime habits.

A Cochrane review of obesity intervention studies undertaken in Western countries has shown that behavioural change interventions alone in adolescents had limited impact, either in the short-term or longer-term [5]. A systematic review of interventions in China among school students revealed that strategies focusing on health knowledge, physical activity and diet had limited beneficial effect for healthy weight [6]. These findings suggest that future obesity prevention programs should include changing school environments to facilitate change in individual behaviours and thus improve the impact and sustainability of obesity prevention programs [5].

Evidence of association between school environment factors and obesity was limited to recent studies on fast-
C Biomed Central

() 2011 Li et al; licensee BioMed Central Ltd. This is an Open Access article distributed under the terms of the Creative Commons Attribution License (http://creativecommons.org/licenses/by/2.0), which permits unrestricted use, distribution, and reproduction in any medium, provided the original work is properly cited. 
food restaurant and retailers in school vicinity [7-9]. Other factors such as availability of sports facilities, school curriculum and policies with weight status and behaviours have been rarely studied [10-12]. The purpose of this study was to identify the school environment factors associated with BMI among school adolescent in Xi'an City to provide evidence for future research and prevention programs in adolescents in urban China.

\section{Methods}

From May to November in 2004, a sample of 1804 adolescents aged 11-17 years representing junior high students in Xi'an City were enrolled in this survey. The mean age of the adolescents was 13.9 years. There were 49.8\% females and $50.2 \%$ male students. A multistage cluster sampling method was used in which 30 out of 183 junior high schools were selected proportionate to school population size (ranging from 258 to 3744 students). In each selected school, one class from each grade was randomly selected and from each class 20 students were selected using systematic random sampling.

Informed signed consent was sought hierarchically from the Municipal Education Department, the school health division at district level, the principal at school level, and finally the participants and their parents. The study protocol was approved by Human Research Ethics Committee at the University of Newcastle and Ethical Committee in Medical Research at Xi'an Jiaotong University.

Height without shoes was measured using a nonstretchable tape suspended from the wall (214 Road RodTM, US) and was recorded to the nearest $0.1 \mathrm{~cm}$. Body weight was measured without shoes but with underwear in the summer session, or light clothes in the autumn session, using a digital scale (Tanita HD-305, Japan) to the nearest $0.1 \mathrm{~kg}$. Anthropometry was collected in schools by trained public health workers using anthropometric standardization reference manual [13]. Parents of the participants were asked to complete a household questionnaire in which the birth date of the participating children, parental education (in years) and self-reported height and weight were included. An inventory of household assets (house, TV, camera, DVD, air conditioner, transportation facilities, and kitchen utensils) was also recorded for computing a wealth index as an indicator of the socioeconomic status of the household [14].

Three groups of school environment factors were included in this study, namely school physical factors, curricula and policies. Physical factors included school size (enrolment), availability of sports facilities (playground measured as $\mathrm{m}^{2}$ per student, oval, gym, and sports equipment), availability of canteen and selected foods and drinks (sweets and chocolates, ice-cream, soft drinks), and western fast food restaurants near school within 10-minute's walk (yes, no). School curricula covered schedules for sports meetings, morning exercises, class recess sports, and physical and health education lessons. School policies included bike riding (forbidding bicycle riding to school), snacking (allowing purchase of snacks at shops in the school), and foods sold at canteen (any regulations). These information was collected by asking school doctors to complete a pre-coded questionnaire (30 items) designed for this survey. Questionnaire items were identified based on three focus group discussions with the local school community stakeholders including staff from the Municipal Education Department, school health workers at district level, school teachers, students and their parents. Following the construction of the questionnaire, a scientific panel meeting at Xi'an Jiaotong University revised the questionnaire. The questionnaire was piloted at schools and further revised before the commencing the survey. Data was analyzed using the statistical package STATA version 10 (2005, STATA Corporation, College Station, TX, USA). Body mass index (BMI) was calculated by dividing body weight in $\mathrm{kg}$ by the square of height in meters. Overweight and obesity were defined using IOTF criteria [15]. BMI was used as the outcome variable in linear mixed effects models [16]. The fixed effect (coefficients) of school environment factors (selected from univariate models $\mathrm{P}<0.25$ ) with their $95 \%$ confidence intervals $(95 \% \mathrm{CI})$ are presented in the results. The factors were adjusted for socio-demographic factors including age, parental education and their BMI, and household wealth. Univariate model was first conducted to screen variables with $\mathrm{P}<0.25$ for multivariate regression [17]. Significant socio-demographic factors were added with school factors in the subsequent models.

\section{Results}

Of the 1804 students invited, 1792 (99.3\%) students consented and had their weight and height measured. All of the 30 school doctors completed the school environment questionnaire. The household questionnaire was completed by 1768 parents of the participants.

Table 1 shows the characteristics of the participating schools, including student enrolments, age, gender distribution, and the prevalence of combined overweight/ obesity. Socioeconomic factors such as parental education and their BMI, and household wealth, are also presented in Table 1. The school prevalence of overweight/ obesity was the lowest in Baqiao district (10.1\%) which is a semi-rural area, and was the highest in Yanta district $(33.4 \%)$ in areas around city centre. Similar district pattern was found with parental education and their 
Table 1 The school characteristics $(n=30)$

\begin{tabular}{|c|c|c|c|c|c|c|c|}
\hline School name & Enrolment & Age (SD) & \%Female & Parental BMI & Parental education (years) & Household wealth * & \%Overweight/obesity ${ }^{* *}$ \\
\hline \multicolumn{8}{|c|}{ Xincheng District } \\
\hline 29th & 258 & $13.8(1.0)$ & 54.1 & 22.1 & 9.4 & -1.0 & 11.5 \\
\hline 89th & 3752 & $13.7(1.0)$ & 50.0 & 22.1 & 11.2 & 0.7 & 21.7 \\
\hline Aizhi & 3095 & $13.7(1.0)$ & 51.7 & 22.9 & 13.5 & 1.9 & 16.7 \\
\hline Huanghe & 2125 & $13.6(1.0)$ & 48.3 & 22.6 & 12.2 & 1.2 & 18.3 \\
\hline Xiguang & 1857 & $13.7(1.0)$ & 49.2 & 22.7 & 13.1 & 1.0 & 15.3 \\
\hline Dahua & 987 & $13.9(0.9)$ & 46.7 & 22.5 & 10.3 & -0.7 & 10.0 \\
\hline Total & 12074 & $13.7(1.0)$ & 50.0 & 22.5 & 11.6 & 0.5 & 15.6 \\
\hline \multicolumn{8}{|l|}{ Beilin District } \\
\hline 8 th & 2277 & $13.6(1.0)$ & 45.8 & 22.7 & 12.1 & 1.3 & 28.8 \\
\hline 82th & 820 & $14.6(1.0)$ & 52.5 & 23.2 & 10.9 & 0.3 & 11.5 \\
\hline Zunde & 534 & $13.6(1.0)$ & 45.0 & 23.1 & 11.3 & 0.6 & 20.0 \\
\hline Jiankeda & 663 & $14.2(0.9)$ & 50.9 & 22.7 & 13.4 & 1.3 & 15.3 \\
\hline Shenjian & 593 & $14.6(1.0)$ & 47.3 & 23.1 & 10.9 & 0.0 & 12.7 \\
\hline Total & 4887 & $14.1(1.1)$ & 48.3 & 23.0 & 11.7 & 0.7 & 17.7 \\
\hline \multicolumn{8}{|l|}{ Lianhu District } \\
\hline 15th & 746 & $14.3(1.1)$ & 48.3 & 22.3 & 10.3 & -1.1 & 11.7 \\
\hline 67th & 1040 & $14.2(1.0)$ & 48.3 & 22.1 & 9.5 & -0.8 & 18.3 \\
\hline Dianli & 1802 & $13.5(1.0)$ & 49.2 & 22.5 & 11.5 & 0.5 & 21.3 \\
\hline YD1st & 2583 & $13.6(1.0)$ & 51.7 & 23.2 & 12.4 & 1.0 & 18.3 \\
\hline YD2nd & 3744 & $13.8(0.9)$ & 61.7 & 22.6 & 10.8 & 0.3 & 20.0 \\
\hline Total & 9915 & $13.9(1.0)$ & 51.8 & 22.6 & 10.9 & 0.01 & 17.9 \\
\hline \multicolumn{8}{|l|}{ Yanta District } \\
\hline 46th & 282 & $14.2(1.1)$ & 48.3 & 23.2 & 8.7 & -1.5 & 15.0 \\
\hline 98th & 1323 & $13.9(1.0)$ & 50.0 & 23.1 & 11.8 & 0.3 & 15.0 \\
\hline Gaoxin & 2957 & $13.7(1.0)$ & 50.0 & 23.3 & 13.7 & 2.2 & 53.3 \\
\hline Dianzi & 1206 & $13.8(1.1)$ & 40.0 & 22.7 & 10.8 & 0.0 & 21.7 \\
\hline Shida & 1506 & $13.6(1.0)$ & 46.7 & 23.1 & 14.4 & 1.8 & 23.3 \\
\hline Total & 7274 & $13.8(1.0)$ & 47.0 & 23.1 & 11.8 & 0.5 & 25.7 \\
\hline \multicolumn{8}{|c|}{ Weiyang District } \\
\hline 16th & 1455 & $14.2(1.0)$ & 51.7 & 22.6 & 9.0 & -0.5 & 10.0 \\
\hline 50th & 1638 & $14.0(0.9)$ & 47.5 & 22.7 & 8.7 & -1.7 & 5.1 \\
\hline 75th & 1044 & $13.8(1.0)$ & 50.0 & 22.9 & 11.2 & 0.5 & 18.3 \\
\hline Shanshi & 1036 & $13.9(1.0)$ & 56.9 & 22.6 & 9.7 & -0.4 & 13.8 \\
\hline Qunxing & 139 & $14.5(1.4)$ & 50.0 & 22.1 & 9.5 & -0.4 & 6.7 \\
\hline Total & 5312 & $14.1(1.1)$ & 51.2 & 22.6 & 9.6 & -0.5 & 10.8 \\
\hline \multicolumn{8}{|l|}{ Baoqiao District } \\
\hline 55 th & 896 & $14.0(1.0)$ & 48.3 & 22.9 & 8.9 & -1.8 & 10.1 \\
\hline 64th & 1318 & $14.1(0.9)$ & 50.0 & 22.1 & 9.7 & -2.6 & 8.3 \\
\hline Luyuan & 581 & $14.0(0.9)$ & 55.0 & 22.5 & 9.2 & -2.2 & 6.7 \\
\hline Dianjian & 878 & $13.7(0.9)$ & 50.0 & 22.7 & 10.6 & 0.1 & 15.0 \\
\hline Total & 3673 & $13.9(1.0)$ & 50.8 & 22.5 & 9.6 & -1.6 & 8.8 \\
\hline
\end{tabular}

* Mean household wealth index per school, household wealth index computed by principal component analysis [14];

**Overweight and obesity was defined by IOTF BMI cut offs [15]

BMI, and household wealth. BMI was significantly associated with age (coef. 0.3, 95\% CI: 0.1-0.4), parental education (coef. 0.8, 95\% CI: 0.5-1.1), parental BMI (coef. 0.3, 95\% CI: 0.2-0.4), and household wealth (coef. 0.3, 95\% CI: 0.2-0.4), but not associated with gender (coef.
$-0.002,95 \%$ CI: -0.3-0.3). Ten out of 20 school environment factors with a $\mathrm{P}<0.25$ in univariate analysis are shown in Table 2. BMI was negatively associated with play ground size, lack of school oval, and forbidding bicycle ride to school, but positively associated with 
Table 2 BMI of and school environment factors in Xi'an City

\begin{tabular}{|c|c|c|c|c|c|c|c|c|}
\hline \multicolumn{2}{|c|}{ School Factors } & \multirow[t]{2}{*}{ School No. or mean (SD) } & \multirow[t]{2}{*}{ Student No. } & \multirow[t]{2}{*}{ BMI (SD) } & \multicolumn{2}{|c|}{ Unadjusted } & \multicolumn{2}{|c|}{ Adjusted $^{*}$} \\
\hline & & & & & Coef $^{* *}$ & $95 \% \mathrm{Cl}$ & Coef** & $95 \% \mathrm{Cl}$ \\
\hline \multicolumn{2}{|c|}{ Playground per person $\left(10 \mathrm{~m}^{2}\right)$} & $0.5(0.4)^{* * *}$ & $\mathrm{~N} / \mathrm{A}$ & N/A & -0.5 & $-1.2,0.3$ & -0.2 & $-0.9,0.4$ \\
\hline \multirow[t]{2}{*}{ School oval } & Yes & 27 & 1619 & $20.0(3.4)$ & \multicolumn{4}{|c|}{ Reference } \\
\hline & No & 3 & 173 & $19.3(3.1)$ & -0.6 & $-1.6,0.3$ & -0.6 & $-1.4,0.2$ \\
\hline \multirow[t]{2}{*}{ Morning exercise } & Yes & 23 & 1379 & $19.9(3.4)$ & \multicolumn{4}{|c|}{ Reference } \\
\hline & No & 7 & 413 & $20.1(3.3)$ & 0.3 & $-0.5,1.0$ & 0.1 & $-0.6,0.7$ \\
\hline \multirow[t]{2}{*}{ Class recess exercise } & Yes & 28 & 1673 & $19.9(3.4)$ & \multicolumn{4}{|c|}{ Reference } \\
\hline & No & 2 & 119 & $20.2(2.9)$ & 0.3 & $-1.0,1.5$ & -0.2 & $-1.8,0.9$ \\
\hline \multirow[t]{3}{*}{ Sports meetings } & twice a year & 13 & 779 & $19.7(3.2)$ & \multicolumn{4}{|c|}{ Reference } \\
\hline & Once a year & 15 & 893 & $19.8(3.3)$ & 0.1 & $-0.4,0.6$ & 0.1 & $-0.3,1.6$ \\
\hline & Once in 2 years & 2 & 120 & $22.0(4.0)$ & 2.2 & $1.2,3.2$ & 1.9 & $1.0,2.8$ \\
\hline \multirow[t]{2}{*}{ Health education } & Yes & 27 & 1614 & $19.8(3.3)$ & \multicolumn{4}{|c|}{ Reference } \\
\hline & No & 3 & 178 & $21.4(3.9)$ & 1.6 & $0.7,2.4$ & 1.2 & $0.4,2.0$ \\
\hline \multirow[t]{2}{*}{ Soft drinks at school shops } & No & 2 & 181 & $19.8(3.2)$ & \multicolumn{4}{|c|}{ Reference } \\
\hline & yes & 8 & 1619 & $21.2(4.1)$ & 1.4 & $0.5,2.3$ & 1.2 & $0.4,2.0$ \\
\hline \multirow[t]{2}{*}{ Fast food outlets } & No & 21 & 1259 & $19.7(3.8)$ & \multicolumn{4}{|c|}{ Reference } \\
\hline & Yes & 9 & 541 & $20.5(3.1)$ & 0.8 & $0.2,1.5$ & 0.7 & $0.1,1.2$ \\
\hline \multirow[t]{3}{*}{ Number Fast food outlets } & 0 & 16 & 954 & $19.2(3.0)$ & \multicolumn{4}{|c|}{ Reference } \\
\hline & 1 & 8 & 477 & $20.3(3.5)$ & 0.8 & $0.1,1.4$ & 0.6 & $-.0 .02,1.1$ \\
\hline & $\geq 2$ & 6 & 361 & $20.5(3.9)$ & 1.0 & $0.3,1.7$ & 0.8 & $0.1,1.4$ \\
\hline \multirow[t]{2}{*}{ Bike riding (allowed) } & Yes & 29 & 1740 & $20.0(3.4)$ & \multicolumn{4}{|c|}{ Reference } \\
\hline & No & 1 & 60 & $18.7(2.4)$ & -1.2 & $-2.9,0.4$ & -0.8 & $-2.2,0.6$ \\
\hline
\end{tabular}

* Adjusted for significant socio-demographic factors including age, parental education, parental BMI, and household wealth Index.

${ }^{* *}$ coefficient of school factors was from linear mixed effect models

*** mean playground per person in $10 \mathrm{~m}^{2}$ with the standard deviation.

lacking of morning exercise, or class recess exercise, or physical health education class, or less frequent sportsmeeting, or the availability of soft drinks at school shops and western fast food outlets in school area. After adjusted for socio-demographic factors, the availability of soft drinks at school and western fast food in schools area were associated with BMI; school curricula such as sport meeting, health education sessions were associated with BMI.

\section{Discussion}

This study indicated the school environment factors such as availability of soft drinks at school and fast food outlet in school area, and school curricula were associated with BMI independent of socio-demographic factors. And number of fast food outlet appeared to be dose responsive with BMI. These results are useful to generate future research hypothesis and to plan obesity prevention programs that include environment components. One future research could be on how availability of soft drinks and fast food outlet influence the dietary habit of students. Another direction could be to evaluate the effect of school curricula modification on individual healthy behaviours such as physical activity, and knowledge about health diet.
The association between fast food outlets around school area and BMI found in this study was consistent with the US studies $[8,18]$, although the effect size varied due to methodological differences in outcome variable and statistical analysis. Children who ate fast food consumed more total energy, more total fat, less fibre, and fewer fruits and non starchy vegetables [19]. Frequent consumption of western fast food was associated with overweight and obesity in Chinese boys [20]. Fast food restaurant use has increased rapidly in urban areas in China and has become popular among children and adolescents massive advertising and marketing campaigns. For example, KFC had 10 restaurants in 1992 and 2500 in 2009, while McDonald's will double its number of outlets in China in the next three or four years to 2,000 by 2015 [21]. Adolescents living in urban areas are socioeconomically better in the present study and are exposed to the obesity-promoting food environment. It is becoming crucial to equip them with healthy diet knowledge and to inform community authorities of the evidence for future city planning to avoid the exposure. This is contrary to the results from recent studies conducted in Canada and New Zealand using GIS that higher density of fast-food outlets in more-socially deprived school areas [22,23]. US studies indicated it is 
the lower price but not the availability of fast food that was associated with BMI [24].

Consumption of soft drinks has been established to be associated with overweight and obesity in adolescents both in western society and developing countries from longitudinal [25] and cross-sectional studies [20,26,27]. The exposure of soft drinks at schools and lack of parents' supervision may increase the consumption of soft drink. A US representative data revealed that sugarsweetened beverages obtained at school contributed a daily mean of $29 \mathrm{kcal}$ in middle school children and 46 $\mathrm{kcal}$ in high school children [28]. The study also showed that attending a school without stores or snack bars was estimated to reduce sugar-sweetened beverage consumption by $22 \mathrm{kcal}$ per school day in middle school children and by $28 \mathrm{kcal}$ in high school children [28]. Chinese health authorities proposed to ban soft drinks at schools following the practice in US, UK, German, and Japan [29].

School curricula such as less sports-meeting and no health education class were associated with higher BMI in Chinese students. Chinese students are under academic pressure due to the examination system and spend most of their waking time attending classes and doing homework [30]. The health authorities and relevant government agencies have decided to tackle the declining health of young people including overweight and obesity in schools, for example, in 2006, the Chinese Ministry of Education launched the Sunshine Sports program to promote physical activity in schools [31]. The aim of the program was to help $85 \%$ school students achieving one hour physical activity and 9-10 hours of sleep within three years for improving their health [31]. Following a success multicenter school intervention project in China to promote physical activity and health knowledge among primary students [32], Beijing Municipal Education Bureau has launched a campaign of " 5 more minutes class recess exercise" [33]. Schools are required to reform the curricula to have physical education and health education session twice a week instead of once a week. The ultimate goal is to have student do at least one hour of physical activity a day in school [33]. Practical school health policies and curricula will be developed and implemented after evaluation of these programs [31-33].

Compared with our previous hierarchical logistic regression model in which factors at the levels of community, school, household, parental and students' individual were studied [10], different school factors were identified. This is not contradictory since each analytic approach aimed to answer different question. The purpose of this analysis was to examine the association between school environment factors and BMI adjusted for socio-demographic factors; while the hierarchical analysis explored the associated risk factors in the presence of all inter-related factors at different levels. The interpretation and understand of the results of the two analysis should be scrutinized.

This study enrolled a representative large sample with high response rate. The outcome variable was collected using standardized objective measurements. In addition, the statistical method took into account both within and between school variations of the school factors. The strength of this study contributed robust and unbiased effect size estimation. Schools in China generally adopt uniform system in management, structure and curricula, so the results from this study are applicable to other schools in China and it serves the first step in understanding the relationship between school environment and BMI to generate future research. In spite of these, the cross-sectional study could not provided causal relationship between school environment factors and weight status. Other factors that associate with BMI at household and community level influencing individual behaviours are not reported in this study.

\section{Conclusions}

School environment factors such as the availability of soft drinks at school, easy access to fast food outlet in school area, and school curricula were associated with students' BMI in Xi'an City, China. Community and school policy makers should make efforts for students to avoid exposure to fast food outlet in school area and soft drinks at school shops, and to improve school curricula to promote sustainable healthy lifestyle behaviours.

\section{Acknowledgements}

This research was sponsored by a research training fellowship (066971/2/02/ A) from the Health Consequences of Population Change Program of The Wellcome Trust. The authors would like to acknowledge Xi'an Municipal Department of Education and Department of Health for their coordination of the study.

\section{Author details}

${ }^{1}$ Division of Health Sciences, University of South Australia, Australia. ${ }^{2}$ College of Medicine, Xi'an Jiaotong University, Xi'an, China. ${ }^{3}$ The School of Public Health, University of Sydney, Australia.

\section{Authors' contributions}

ML contributed to study design, project management, data collection and analysis, manuscript preparation. MJD participated study design, supervising data collection and manuscript revision. $\mathrm{YH}$ involved in supervision of data collection and project management. All authors read and approved the final manuscript.

\section{Competing interests}

The authors declare that they have no competing interests.

Received: 3 May 2011 Accepted: 11 October 2011

Published: 11 October 2011

\section{References}

1. Wang L: National Nutritional and Health Survey Report One-Overall Report Beijing People's Health Publishing House; 2005. 
2. Li M, Dibley M, Sibbritt D, Yan H: An assessment of adolescent overweight and obesity in Xi'an City, China. In J Pediatric Obes 2006, 1:50-58

3. Swinburn B, Egger G, Raza F: Dissecting obesogenic environments: the development and application of a framework for identifying and prioritizing environmental interventions for obesity. Prev Med 1999, 29:563-570.

4. Davison KK, Birch LL: Childhood overweight: a contextual model and recommendations for future research. Obes Rev 2001, 2:159-171.

5. Summerbell CD, Waters E, Edmunds LD, Kelly S, Brown T, Campbell KJ: Interventions for preventing obesity in children. Cochrane Database Syst Rev; 2005, CD001871.

6. Li M, Li S, Baur LA, Huxley RR: A systematic review of school-based intervention studies for the prevention or reduction of excess weight among Chinese children and adolescents. Obes Rev 2008, 9:548-559.

7. Howard PH, Fitzpatrick M, Bulfrost B: Proximity of food retailers to schools and rates of overweight ninth grade students: an ecological study in California. BMC Public Health 2011, 11:68.

8. Davis B, Carpenter C: Proximity of fast-food restaurants to schools and adolescent obesity. Am J Public Health 2009, 99:505-510.

9. Laska MN, Hearst MO, Forsyth A, Pasch KE, Lytle L: Neighbourhood food environments: are they associated with adolescent dietary intake, food purchase and weight status. Public Health Nutr 2010, 13:1757-1763.

10. Li M, Dibley M, Sibbritt D, Yan H: Factors associated with adolescents overweight and obesity at community, school, and household levels in Xi'an City, China - results of hierarchical analysis. Eur J Clin Nut 2008, 62:635-643.

11. Li M, Dibley M, Sibbritt D, Yan H: Factors Associated with Adolescents' Physical Inactivity in Xi'an City, China. Med Sci Sports Exerc 2006 38:2075-2085

12. de Vet E, de Ridder DTD, de Wit JBF: Environmental correlates of physical activity and dietary behaviours among young people: a systematic review of reviews. Obes Rev 2011, 12:e130-e142.

13. Lohman TG, Roche AF, Martorell R: Anthropometric standardization reference manual.Edited by: Abridged. Champaign: Human Kinetics; 1991:

14. Filmer D, Pritchett $L$ : Estimating wealth effects without expenditure dataor tears: An application to educational enrolments in States of India. World Bank Policy Research Working Paper No. 1994 World Bank, Washington; 1998.

15. Cole T, Bellizzi M, Flegal K, Dietz W: Establishing a standard definition for child overweight and obesity worldwide: international survey. BMJ 2000, 320:1240-1243.

16. Singer JD: Using SAS PROC MIXED to fit multilevel models, Hierarchical models, and individual growth models. J Educ Behav Stat 1998, 24:323-355.

17. Hosmer D, Lemeshow S: Model-building strategies and methods for logistic regression. In Applied logistic regression. Edited by: Hosmer D, Lemeshow S. New York City: John Wiley 1989:82-126.

18. Currie J, DellaVigna S, Moretti E, Pathania V: The effect of fast food restaurants on obesity and weight gain. Am Econ J Econ Policy 2010 2:32-63.

19. Bowman SA, Gortmaker SL, Ebbeling CB, Pereira MA, Ludwig DS: Effects of fast-food consumption on energy intake and diet quality among children in a national household survey. Pediatrics 2004, 113:112-118.

20. Li M, Dibley M, Sibbritt D, Yan H: Dietary habits and its association with overweight/obesity among Chinese adolescents. Asia Pac J Clin Nutr 2010, 19:76-82.

21. The icandata Research Center: The growth of fast-food restaurant in China-market status and development.[http://www.icandata.com/tc/ baogao/200902/0219294452009.html].

22. Kestens $Y$, Daniel M: Social inequalities in food exposure around schools in an urban area. Am J Pre Med 2010, 39:33-40.

23. Day $\mathrm{PL}$, Pearce J: Obesity-promoting food environments and the spatial clustering of food outlets around schools. Am J Pre Med 2011, 40:113-121.

24. Powell LM, Han E, Chaloupka FJ: Economic contextual factors, food consumption, and obesity among U.S. adolescents. J Nutr 2010, 140:1175-1180.

25. Ludwig D, Peterson K, Gortmaker S: Relation between consumption of sugar-sweetened drinks and childhood obesity: a prospective, observational analysis. Lancet 2001, 357:505-508.
26. Nicklas TA, Yang S, Baranowski T, Zakeri I, Berenson G: Eating pattern and obesity in children: The Bogalusa Heart Study. Am J Pre Med 2003, 25:9-16.

27. Hesketh T, Ding Q, Tomkins AM: Disparities in economic development in Eastern China: impact on nutritional status of adolescents. Public Health Nutr 2002, 5:313-318.

28. Briefel RR, Crepinsek MK, Cabili C, Wilson A, Gleason PM: School food environments and practices affect dietary behaviours of US public school children. J Am Diet Assoc 2009, 109:S91-S107.

29. Fu L: Sugar consumption-a global treat to health-a Life times report. [http://www.bjwmb.gov.cn/zxfw/wmwx/kxbj/t20110715_398172.htm].

30. Li M, Dibley M, Sibbritt D, Yan H: Physical activity and sedentary behavior among Xi'an adolescents. J Adolesc Health 2007, 41:99-101.

31. Ministry of Education: National-wide initiative of Sunshine Sports program among school students.[http://www.tjtdxy.cn/show.aspx?id = $1538 \&$ cid $=70]$.

32. Li Y, Hu X, Zhang Q, Liu A, Fang H, Hao L, Duan Y, Xu H, Shang X, Ma Jun, et al: The nutrition-based comprehensive intervention study on childhood obesity in China (NISCOC): a randomised cluster controlled trial. BMC Public Health 2010, 10:229.

33. Zhang L: Students in Beijing will have 5 more minutes doing class recess exercise.[http://news.xinhuanet.com/edu/2011-06/05/c_121496560.htm].

\section{Pre-publication history}

The pre-publication history for this paper can be accessed here: http://www.biomedcentral.com/1471-2458/11/792/prepub

doi:10.1186/1471-2458-11-792

Cite this article as: Li et al: School environment factors were associated with BMI among adolescents in Xi'an City, China. BMC Public Health 2011 11:792.

\section{Submit your next manuscript to BioMed Central and take full advantage of:}

- Convenient online submission

- Thorough peer review

- No space constraints or color figure charges

- Immediate publication on acceptance

- Inclusion in PubMed, CAS, Scopus and Google Scholar

- Research which is freely available for redistribution

Submit your manuscript at www.biomedcentral.com/submit
C) Biomed Central 